\title{
An Analytical Study of Determinants of Poverty Level among Households in Adamawa North District, Nigeria
}

\author{
Salami L.A ${ }^{1}$ \\ Atiman $\mathrm{K}^{2}$ \\ ${ }^{1}$ Department of Economics, Adamawa State University, Mubi-Nigeria \\ 2 Department of General Studies, Federal Polytechnic, Bali-Nigeria
}

\section{Doi:10.5901/mjss.2013.v4n16p73}

\begin{abstract}
The study focused on analysis of poverty determinants among households in Adamawa North Senatorial District. Primary data were generated through structured questionnaire and interview. Using a multistage sampling approach, a total of 400 households were selected and interviewed. Data collected were subjected to Foster Greer and Thorbecke (FGT) and linear regression analysis. Considering some poverty indicators, the study revealed that using the FGT model of assessment, 86.3 percent of the households covered by the study were poor and would have to mobilize financial resources up to $41.80 \%$ of $\$ 2$ US (N300) per day (for each household member) to be able to escape poverty. Result of linear regression also showed that coefficients of educational levels of household, occupation, energy of household are 0.068, 0.36 and 0.25 respectively, while dependency ratio, sources of water, poor feeding shown inverse relationship of $-0.19,-0.10,-0.19$ respectively. These are factors that exert significant influence on household per capita income in the study area. In order to reduce poverty and promote peoples' income, policies that would promote employment opportunities, educational status of household, as well as efforts to enhance women access to more productive resources and investment in infrastructural development are recommended.
\end{abstract}

\section{Keywords: Determinants, Poverty, Mubi region, Adamawa State}

\section{Introduction}

The global call for sustainable development has coincided with an emphasis on poverty alleviation in the 1990 's. This is more pertinent to Sub-Saharan Africa where on the average, $45 \%$ - $50 \%$ of the people live below the poverty line, a much higher proportion than in any other region of the world except South Asia (Mbaku, 1994 and World Bank, 1996). Poverty is one of the main manifestations of underdevelopment and its reduction is generally considered synonymous with development (Karaosmanoglu, 1989). It has an adverse effect on the people, its national economy and the political/social development of the affected countries. Thus, poverty is currently attracting varying degrees of attention.

In particular, poverty is increasingly being studied by International Organizations such as the World Bank and some specialized organ of the United Nations Organization i.e., the United Nation Development Programme (UNDP). Nevertheless in Nigeria there is still a considerable lapse in the concept, measurement, and determinants of poverty. In the 1980's, there were few analysis on the causes of poverty in Nigeria (World Bank, 1990; Ogwumuke \& Ekpenyong, 1996). Despite the intellectual leadership of the World Bank, there is still a considerable amount of work to be done. Developing a consistent poverty oriented policy depends on understanding the concept of poverty and analyzing its determinants with a view to providing practical ways of alleviating it.

Based on statistical analysis, one billion people in the world are living on less than a dollar/day; 2.7 
billion people in the world are living on less than two dollars a day; 11 million children die every year as a result of poverty; 114 million children are not able to acquire basic education and 584 million women are illiterate. Every year, 6 million children die as a result of malnutrition. Every day, 800 million people stay hungry in which 300 million are children. About 2.6 billion people (38\% of the world's population) are deprived from basic sanitation and 1 billion people do not have access to safe drinking water (United Nation Development Programme, 2002 Survey).

In Nigeria, the incidence of poverty has been on the increase. It rose from 28.1\% (18.26 million) in 1980 to $46.3 \%$ (34.37 million) in 1985 and to 65.6\% (68.70 million) in 1996 (National Bureau of Statistics, 2006). Even though it fell to $54.4 \%$ in 2004 , the population of Nigerians within the poverty line has been on the increase with the number of urban poor taking the lead (Ruel, 2008).

Analyses on geo-political zones basis showed that the North West and North East zones accounted for the highest poverty rates with 77.7 per cent and 76.3 per cent respectively. The South West, with 59.1 per cent, recorded the lowest poverty rate in the country. A further analysis of the poverty level on state-by-state basis showed that Sokoto had the highest number of poor in the country with 86.4 per cent of its population recorded as not enjoying good living standards compared to Niger State which had the lowest poverty rate of 43.6 per cent by end 2010. Thus, using the relative, absolute and dollar-per-day poverty measures, NBS estimates that poverty may have further risen slightly to 71.5 per cent, 61.9 per cent and 62.8 per cent respectively in 2011," (National Bureau Statistics 2011).

Several ambitious programs and projects have been adopted in the past to check the increasing poverty rate in Nigeria. It is also worthy to note that most of these projects failed to achieve their specified objectives and targets. Mubi region with its unique socio-economic group, different sources of income and determinants of poverty, research has not been carry out in this life threatening area especially using quantitative analysis as this study trying to do. In view of these, this study was set out to analyze the determinants of poverty among households and the impact in the study area.

\section{History of the Study Area}

Mubi region of today was the then northern part of old sardauna province which now forms Adamawa Northern Senatorial District. The region lies between latitude $9030^{\prime \prime}$ and $11^{\circ} 33^{\prime \prime} \mathrm{N}$ of the equator and longitude 13:00 $\mathrm{E}$ and 13: $45^{\circ}$ East of the Greenwich-meridian. The region is bounded in the north by Borno State, in the west by Hong and Song LGAs and in the south and east by the Republic of Cameroon. It has a land area of $4728.77 \mathrm{~km}^{2}$ and a population of 681,353 in the 2006 National population census.

Mubi region was part of Northern Cameroon under the Germans until 1922 when the area was placed by the United Nations under Britain as a "Trusteeship Territory". The area was then subjected to the administration of Northern Nigeria. It remained so until 1961, when a plebiscite was conducted for the people to decide either to be part of the Independent Nigeria or they join the Cameroon Republic. The people voted in favor of Nigeria and hence the Northern-Cameroon was incorporated into the Federation of Nigeria on $1^{\text {st }}$ June, 1961 (Nwafor, 1982).

Thereafter, the erstwhile Trusteeship Province was renamed Sardauna Province in honor of the then premier of Northern region, Sir Ahmadu Bello. The region is now the Mubi Emirate Council. Today, the region consists of five LGAs namely, Madagali, Maiha, Michika, Mubi North and Mubi South (Adebayo 2004).

The inhabitants of Mubi region are mainly farmers and few civil servant as well as those with private businesses. As an agrarian community, virtually all the households in the area engage in one form of farming or the other, but mostly at subsistence level. Generally, the bulk of the crop production takes place under traditional system without the use of mechanical power. 


\section{Research Method}

The data for this study were generated from primary source. The data were collected through general household's survey and administration of structured questionnaire. The survey covered notable areas in each local government, like, Michika town, Maiha town, Sabo-laye, Wuropatuji, Madagali town and Yeluwa in Mubi town.

Sample sizes of four Hundred (400) respondents were randomly selected and Questionnaires were administered to obtain the information required, out of which 389 answered were returned. Stratified Random Sampling Technique was used. This was achieved by dividing the population into stratum or sub-population of the households in the study area to allow good degree of representation.

\section{Analytical Techniques}

\subsection{Foster-Greer-Thorbecke (FGT) Poverty Model}

Although a large literature on approaches to poverty measurements exists, however, the chosen measure of poverty must be able to capture a range of judgments on the extent and significance of poverty, at the same time it must be easy to handle and interpret. One set of measures that have been found to be appropriate are those proposed by (Foster, et al 1984).

The analysis of poverty status using FGT measure of poverty involves the ranking of incomes in the ascending order of magnitude such that:

$Y_{1 i} \leq Y_{2 i} \leq \ldots \leq Y_{q i} \leq Z_{i} \leq Y_{(q+1) i} \leq Y_{(q+2) i} \leq \ldots \leq Y_{n i}$

The FGT measure for the ith sub-group is given by:

$P_{\alpha}=\sum_{i=1}^{q} n i\left(1-Y_{i} / Z\right)^{\alpha} / N$, for $\alpha=0,1,2$

Where,

$\alpha=$ a non-negative parameter;

$Y_{i}=$ income per person in the ith household;

$n i=$ the size of the ith household;

$q=$ the number of households below the poverty line;

$Z=$ the poverty line value or threshold value of income; and

$N=$ the number of persons in the sampling population.

When $\alpha=0$, it implies zero concern for poverty incidence or depth. Equation (1) then reduces to a headcount of poverty. That is,

$$
P_{0 i}=\sum_{i=1}^{q} n i\left(1-Y_{i} / Z\right)^{0} / N
$$

When $\alpha=1$, it conveys the information that there is uniform concern for poverty depth. Consequently, equation (2) becomes,

$$
P_{1 i}=\sum_{i=1}^{q} n i\left(1-Y_{i} / Z\right) / N
$$

Where $P_{1 i}$ is the poverty gap between the ith poor household and the poverty line.

Following from equations (2) and (3), the income gap ratio, which measures the proportionate distance of the mean income of the poor below the poverty line is estimated as the ratio of $P_{1 i}$ to $P_{0 i}$ (i.e. $\left.P_{1 i} / P_{0 i}\right)$.

Finally, when $\alpha=2$, it implies that a distinction is made between the poor and poorest. Equation (1) then reduces to the FGT index, which is a distinctive index of the severity of poverty. FGT for the ith group is given as: 


$$
P_{2 i}=\sum_{i=1}^{q} n i\left(1-Y_{i} / Z\right)^{2} / N
$$

A regression analysis was estimated to establish the determinant of household poverty by using per capita household expenditure/consumption as dependent variable, and also other household characteristics or community factors as the independent variables.

The explicit form of the equation is specified as;

$Y=F(X)$

$Y_{1}=a_{0}+b_{1} x_{1}+b_{2} X_{2}+b_{3} X_{3}+b_{4} X_{4}+b_{5} X_{5}+b_{6} X_{6}+b_{7} X_{7}+b_{8} X_{8}+b_{9} X_{9}+b_{10} X_{10}+b_{11} X_{11}+b_{12} X_{12}+b_{13} X_{13}+b \times 14+u_{i}$

Where $Y=$ Dependent variable

$\mathrm{X}_{1} \mathrm{X}_{2}=$ Independent Variables

$a_{0}=$ constant/slope

$b_{1} b_{2}=$ coefficient of regression

$\mathrm{Y}_{1}=$ Household per capita income $(\mathrm{N})$

$\mathrm{X}_{1}=$ Gender of household ( $0=$ female, $1=$ male),

$\mathrm{X}_{2}=$ Marital Status, $\mathrm{X}_{3}=$ Household age (years),

$\mathrm{X}_{4}=$ Dependency Ratio (member in family),

$X_{5}=$ Educational Qualification,

$X_{6}=$ Occupation of Respondents, $X_{7}=$ Expenses on food $(N)$,

$X_{8}=$ Living Apartment, $X_{9}=$ Toilet (Types),

$X_{10}=$ Sources of Drinking Water,

$X_{11}=$ Sources of Energy, $X_{12}=$ Rate of Death

$X_{13}=$ Poverty Alleviation Programme,

$X_{14}=$ Rate of Beneficiary PAP,

Ui $=$ Error term.

\section{Results and Discussion}

The Foster, Greer and Thorbecke model employed in this study for measuring impact of poverty on households in Mubi region. The international poverty line of US\$2 per day per person is adopted for this study. This will translate to N300.00 per day at exchange rate of N150 per dollar (this was the prevailing rate during the period of survey). Thus, any respondent whose per capita income per month falls below N 10,000 is considered poor.

Table 1: Foster-Greer-Thorbecke (FGT) class of poverty measures for the study sample, 2012.

\begin{tabular}{ll}
\hline FGT Measures & Poor Households \\
\hline 1. When $\alpha=0$, & $\frac{327}{389}=0.84$ \\
$P_{0 i}=\sum_{i=1}^{q} n i\left(1-Y_{i} / Z\right)^{0} / N$ & \\
2. When $\alpha=1$, & $\frac{334}{389}=0.85$ \\
$P_{1 i}=\sum_{i=1}^{q} n i\left(1-Y_{i} / Z\right) / N$ & $\frac{338}{389}=0.86$ \\
3. When $\alpha=2$, & $P_{2 i}=\sum_{i=1}^{q} n i\left(1-Y_{i} / Z\right)^{2} / N$
\end{tabular}

Source: Survey, 2013

To determine and describe the extent and manifestations of poverty among all respondents (i.e. poor and 
non-poor households), the FGT measures of poverty were also employed. The FGT model allowed the estimation of the headcount, the poverty incidence and the poverty gap for the sample. Table 1. presents the results of the poverty analysis using the FGT model.

When $\alpha=0$, it implies that there is zero concern for poverty incidence or depth. The poverty measure given by $P_{0 i}$ then reduces to the headcount measure of poverty. For the poor respondents, the $P_{0 i}$ value was 0.84. This implies that 84 percent of the respondent households were actually poor. This proportion invariably represents the poverty incidence among the sample, and expectedly agreed with the earlier estimation of the proportion of the poor households (i.e. 84 percent) in the sample based on the poverty line definition. When $\alpha=1$, it conveys that there is uniform concern for poverty depth among the study sample. The $P_{1 i}$ value for the poor households in the sample was 0.85 . This implies that poor households required 64percent of the poverty line to get out of poverty. The value of the poverty gap for the poor households in the sample is thus $\mathrm{N} 102,000$ (or 0.85 multiplied by N120,000 p.a).

Finally, when $\alpha=2$, it implies that a distinction is made between the poor and the poorest. This follows since the poverty gap or depth is not sensitive to re-distribution among the poor. The assumption with the poverty gap is that a Naira gained by the poor would have the same effect on poverty as that gained by the moderately poor. As such, to capture the sensitivity to income re-distribution among the poor and non-poor, there exists the need to estimate the severity of poverty among the study sample. The $P_{2 i}$ value for the poor using the FGT model was 0.86 . This conveys that the severity of poverty among the poor households in the study area is 86 percent. This result concurs with the work of John and Salami (2011) on poverty gap, severity and incidences.

\section{Determination of the Factors Affecting the Per Capita Expenditure of the Sampled Households}

As mentioned in the analytical procedure, a functional relationship was formulated to ascertain the determinants of household per capita income on basic needs using the multiple regressions run with Statistical Package (SPSS 15.0 version). In order to analyze the determinants of poverty among households in the study area, the regression function of the form below was fitted to the study data using the ordinary least squares method.

$$
\begin{aligned}
& Y_{1}=a_{0}+b_{1} X_{1}+b_{2} X_{2}+b_{3} X_{3}+b_{4} X_{4}+b_{5} X_{5}+b_{6} X_{6}+b_{7} X_{7}+b_{8} X_{8} \\
& +b_{9} x_{9}+b_{10} x_{10}+b_{11} x_{11}+b_{12} X_{12}+b_{13} x_{13}+b \times 14+b_{15} x_{15}+u_{1} \ldots \ldots \ldots \ldots . . . .7
\end{aligned}
$$

Table 2: Result of Regression model

\begin{tabular}{|l|c|c|c|c|}
\hline \multicolumn{1}{|c|}{ Predicators } & Coefficient & Std Error & t-values & Probability \\
\hline Constant & 8.905 & 2.34 & 4.996 & 0.56 \\
Qualification of Respondents & 0.068 & 0.035 & 1.719 & $0.010^{\star \star \star}$ \\
Marital Status of Respondents & 0.161 & 0.05 & 1.731 & 0.057 \\
Age of household & -0.002 & -0.00 & -0.238 & 0.013 \\
Gender & 0.141 & 0.073 & 1.537 & $0.001^{\star}$ \\
Occupation & 0.363 & 0.123 & 1.143 & 0.017 \\
Dependency ratio & -0.197 & -0.012 & -2.080 & $0.051^{\star \star}$ \\
Food & -0.19 & -0.001 & 0.886 & 0.013 \\
Housing & 0.172 & 0.091 & 1.562 & $0.015^{\star \star \star}$ \\
Toilet & 0.093 & 0.0451 & 1.934 & $0.001^{\star}$ \\
Water Sources & -0.107 & -0.012 & -1.19 & 0.001 \\
Energy Sources & 0.25 & 0.121 & -2.42 & $0.015^{\star \star \star}$ \\
PAP & 0.7 & 0.353 & 1.92 & $0.050^{\star \star}$ \\
Dearth Rate & 0.046 & 0.021 & 1.46 & 0.021 \\
R-Square & .684 & & & \\
\hline
\end{tabular}




\begin{tabular}{|l|l|l|l|l|}
\hline F - value & 20.0 & & & \\
DW Statistic & 0.96 & & & \\
\hline
\end{tabular}

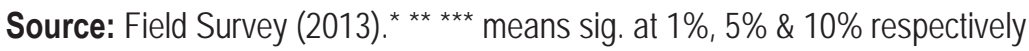

The result of the estimated regression model is presented in Table 4.5 The coefficient of multiple determinations $\left(R^{2}\right)$ with value 0.684 implies that the regressors in the equation explain $68.4 \%$ of the systematic total variation in the household income per capita. The significance of the F-value (20.0) implies that all the explanatory variable jointly exert significant influence on household welfare (as proxied by household income per capita). The F-value of 20.00 is significant, easily passing the significance test at the $1 \%$ level.

Thus, there is no doubt that there exists a significant linear relationship between per capita income of respondent in Mubi region and the regressors used. Out of the fourteen (14) explanatory variables used in the regression model, only seven (07) were significant at different percentage level. They are gender of household, educational level of respondent, dependency ratio, toilet, and energy, housing facilities plus poverty alleviation programme. The other important variables that measuring poverty level in Mubi region includes Poverty Alleviation programme, sources of energy and sources of drinking water which have negative signs, confirming that poor per capita income of the people in Mubi region can be traced to unavailability of these variables. Therefore, there is overwhelming evidence that poverty alleviation scheme like credit facilities and promotion of small and medium scale enterprises are positive factors in addressing menace of poverty in the study area.

The result shows that there is a positive and significant relationship between the gender of household respondent and economic welfare of the household which suggests that an average male household in Mubi region seems better in terms of their economic welfare or living conditions than female household in the study area.

Empirical study by Adeyeye (2004) in Nigeria indicates men have more access to formal education and other productive resources in Nigeria than their women counterpart (although great deal of efforts are now been made to close the gap). This disparity, among others, is the reason for better economic advantage being enjoyed by men in the country. Ability to work, become more productive, earn higher income and improve the standard of living of household members is contingent on access to productive resources. Limited access to these resources has however, constrained women to remain for long on low-paying jobs and especially in the informal sector with its attendant negative implication on their welfare and the households headed by them.

Educational level of respondents and that of marital both have positive influence effect on household welfare (measured by household per capita income). This implies that an additional year gained by the respondents in acquiring education would lead to rise in household income and by implication, the welfare of household members. Educational attainment enhances human capital and participation in labour market and has been widely accepted as a veritable tool for poverty reduction and improving peoples' welfare.

The coefficients 0.068 and 0.161 of households suggest that an additional year in their education level is expected to result in 6.8 and $16.1 \%$ increase in household per capita income. Dependency ratio exacts a negative impact on household per capita, suggesting that increase in dependency ratio (an increase in household size which translates to increases in the number of dependants) would result in reduction in the income resources available to cater for the needs of each household member.

The decline in the per capita income (resource) availability is an indication of down spiral living conditions of household members. The coefficient -0.197 of dependency ratio implies that a unit increase in the dependency ratio will lead to $19.7 \%$ decrease in the household consumption per capita. This scenario also poses a serious threat on the welfare of members of households in the study area, especially among the low- income poor. 


\section{Conclusion}

The definition of poverty by residents of area under study was about the same. They see poverty in terms of hunger, not occasional but perpetual hunger, living in poor housing conditions without water, kitchen and toilet facilities, inadequate income, malnutrition, lack of access to social services, and lack of social and political status. Generally, they see poverty as a lack of command over basic consumption needs like foods, clothes, and shelter, as well as lack of certain capacities, such as being able to participate with dignity in society. It is a situation in which one suffers because of lack of basic needs of substance.

From our analysis, It was found that the urban households, especially the poor were functionally literate as the study reveals that only about $35 \%$ of the poor had no formal education while about $65 \%$ either had primary, secondary, tertiary or informal education. Out of the total households in the study area only $18 \%$ had no formal education while $82 \%$ are educated. Though the some of the households are educated, it showed from the study that $49 \%$ are either unemployed or self-employed. About $71 \%$ of the poor households lived in either single rooms or rooms and parlor. Most of these houses do not have adequate conveniences like running water, toilet and kitchen and in place where they had; many household had to share the facilities. Many cooked their food in their room or in the corridors and used polluted well water as drinking water.

For the residents of Mubi region of Adamawa State to be able to cope with poverty, the poor among them dependent mostly on re-adjusting their expenditure patterns and savings, feeding, clothing and education of children. Infact, majority of the households either fail to save at all or save less than $10 \%$ of their income. The regression result showed education and Income as determinants of monthly or annual households' per capita expenditure on basic needs, however, the relatively low $\mathrm{R}^{2}$ is indicative of the effect of omitted variables.

The inequality in income or wealth distribution and the existence of different poverty levels can be accounted for by unequal opportunities to get the same level of education, the type of occupation of the household, and partly due to the difference in the number of household size and the number of people working in the household; totality of which resulted in difference in the level of poverty among the households.

\section{Recommendation}

i. The Government Poverty Alleviation Programme should be restructured if not re-designed and should be centered on the 'basic needs' approach. This approach emphasizes the importance of separating generalized increase in income from the more significant attainment of the requirements for a permanent reduction of poverty through the provision of health services, education, housing sanitation, water supply and adequate nutrition.

The rationale of this approach was that the direct provision of such goods and services is likely to relieve absolute poverty more immediately than alternative strategies. Since growth strategies usually fail to benefit the intended target and the productivity and income of the poor depend in the first place on the direct provision of health and education facilities. In the same vein, there is no guarantee that increased income will be spent on essential services, since, households vary in their ability to spend wisely and effectively. They may irrationally prefer 'better' consumption goods that contribute less to family welfare than other goods that might serve as inputs to higher productivity.

ii. Therefore, efforts to reduce poverty are unlikely to succeed in the long run unless there is greater investment in the human capital of the poor. Based on the finding of this study, education is strong determinant of poverty, apart from Government and NGO's efforts towards improvement in education; the stake holder in the study areas needs to embark on establishing community primary and secondary schools. And educative forum where aggressive campaign and encouragement towards reasons for acquire education should be organized in Mubi,Michika, Maiha and Madagali 
town for the youth.

iii. Since good health and adequate nutrition directly address the worst consequences of being poor. And also raise workers productivity and earning; there is poor medical facility in the surveyed. Apart from state hospital Mubi and in Michika, any complications have to travel to neighboring cities like Yola or Maiduguri for treatment. More health centres should be constructed and maintained by Government and communities of the study area respectively.

\section{References}

Adebayo A. A (2004). Mubi Region, A Geographical Synthesis, Paradete Publishers Yola, Nigeria.

Adeyeye, V.A (2004) "Rural Crises in Nigeria: Increase in Food Deficits. Decline in Real Income and widespread Rural Poverty" paper presented at the second 1987 NISER Seminar series, Jan 28.

Adeyeye, V. A (1999) "Designing Social Safety Nets for Rural Poor". University of Ibadan Press, Ibadan, p 132.

John N. and Salam L. (2011). Analysis of Poverty Gap, Severity and Incidence among Household in Mubi town. Maiduguri Journal of Art and Social Science. p 66-71.

Karaosmanoglu, N .A (1989). Conceptual Issues Evidence and Policy choices for Developing Countries" Menlo NISER, Ibadan. p. 111-112.

Mbaku, A. B. (1994). "Measurement of Poverty" Oxford University Press, London .p. 149-152.

National Bureau of Statistics (2006) Poverty Profile in Nigeria. Technical Report .

National Bureau of Statistics (2011) Poverty Profile in Nigeria. Technical Report. .

Nwafor, A. C. (1982). "Are the Rural Poor Really Benefiting from SAP? Technical Report, NISER, Ibadan. 5:103-105

Ogwumike and Ekpenyong (1996) "Economic Growth in Nigeria". Macmillan Press, Lagos. p. 211

Ruel K. (2008) "Poverty: Concepts, Measurement and Determinants" Proceeding of Nigerian Economic Society Conference on Poverty Alleviation in Nigeria, Dept. of Economics, University of Ibadan, Ibadan.

United Nations Development Programme Report (2005): Poverty on Human Development", Washington D.C.

World Bank (1990), Economic Review 4;19-21. Washington D.C, U.S.A.

World Bank (1996) "Focusing Africa" - An Economic Review 10:119-122. 